\title{
Prepregnancy Pertussis Immunization: Effect on Materno-Neonatal Antibody Titers and Infant Immune Response to Whole-Cell Pertussis Vaccination
}

Mohammed-Jafar Saffar ${ }^{4}$, Abolghasem Ajami ${ }^{2 *}$, Narges Moslemizadah ${ }^{3}$, Hiva Saffar ${ }^{4}$ and Ali-Reza Khalilian ${ }^{5}$

${ }^{1}$ Professor of Pediatric infectious Disease, Department of Pediatrics, Mazandaran University of Medical Sciences, Booali Sina hospital, Pasdaran Boulevard, Sari, Iran ${ }^{2}$ Molecular and Cell-Biology Research Center, Faculty of Medicine, Mazandaran University of Medical Sciences, Sari ,Iran

${ }^{3}$ Obstetrics-Gynocology Department, Mazandaran University of Medical Sciences, Sari-Iran

${ }^{4}$ Biostatistics department, Mazandaran University of Medical Sciences, Sari-Iran

${ }^{5}$ Pathology department, Shariati Hospital, Tehran University of Medical Sciences, Tehran, Iran

\begin{abstract}
Background: Despite high vaccine coverage the incidence of pertussis is increasing, especially in infants too young to be actively immunized.

We sought to determine whether prepregnancy pertussis boosting could provide higher levels of maternal antibodies to offspring compared with that before one, and also, possible influences on infant immune response to whole-cell pertussis immunization.

Methods: A total of 114 childbearing age women, candidate for pregnancy were boosted with one dose of diphtheria - tetanus, pertussis adult formulation vaccine (dTap). Blood samples were obtained at before and after vaccination and at months of $1,12,28$, and 43 . Paired maternal-neonatal sera were also collected at the time of delivery. Moreover, blood was drawn to examine the infant immune response to scheduled whole - cell pertussis (wP) vaccine after receiving the first, third and fourth dose of the vaccine. Antibodies to pertussis antigens were measured by ELISA method and paired t-test was applied to analyze the data.
\end{abstract}

Results: Seroprevalence rate and the mean concentration of antibodies (MCA) before boosting were $69.3 \%$ and 68.19 EU/ml which increased to $93.8 \%$ and $152.82 \mathrm{EU} / \mathrm{mL}$ after vaccination, respectively. After 43 month, $72.3 \%$ of vaccinees preserved significantly higher $(76.71 \mathrm{vs} .68 .19 \mathrm{Eu} / \mathrm{ml})$ antibody levels compared with prebooster MCA level. Efficient placental transfer of antibody to the offsprings was observed, however, infants immune response to WP vaccine was not influenced by maternal antibodies.

Conclusion: Targeted prepregnancy pertussis immunization provides a higher antibody level at delivery and importantly does not affect infants immune response to WP immunization.

Keywords: Pertussis; Prepregnancy pertussis booster; DTwP; Pertussis antibody dTap; Maternal antibody; Neonatal pertussis

\section{Introduction}

Pertussis is a highly contagious vaccine preventable respiratory infectious disease worldwide. It occurs at any age, but the high incidence of pertussis cases among young infants $[1,2]$ reflect non-protective levels of maternal pertussis-related antibodies, increased exposure to pertussis, or a combination of both $[3,4]$. Severe pertussis in infants too young to be protected by active immunization remains significant health problem both in developed and underdeveloped countries [5-7]. Evidences suggest that household contacts are the commonest source of infection for susceptible infants [8-10].

To reduce pertussis in early infancy several strategies have been proposed to protect the newborns [11-16]. This strategies include: indirect protection by selective vaccination of neonate close contacts [12] and/or universal adescents-adults booster immunization [11]; or direct protection via Pertussis vaccination beginning at birth $[13,14]$ and maternal immunization $[15,16]$. Although the levels of antibodies required for protection against pertussis is not well defined, but higher levels of antibodies seems to correlate with protection $[17,18]$. If maternal immunity is to protect the newborn, a protective levels of specific-IgG antibody must be present in the mother's blood at a time when it can be transferred to the fetus $[3,4]$. The higher concentration specific antibody the fetus received above the protective level, the longer time protection will be maintained after birth. In this regard, enhanced maternal immunity against Pertussis provides neonatal protection since birth to some weeks of life. This period correlates directly with antibody titers achieved by newborn "higher levels, longer protection" $[3,4,15,16]$.

This two-phase study was carried out with the following objectives:

- To determine the kinetics of pertussis antibodies in a cohort of childbearing age women after a diphtheria - tetanus - acellular pertussis adult formulation vaccine (dTap) booster immunization (as a prepregnancy boosting) over a period of 43 months.

- To measure the materno - neonatal transfer ratio of pertussis IgG antibodies, and also, the possible influence of maternally

*Corresponding author: Abolghasem Ajami, Molecular and Cell-Biology Research Center, Mazandaran University of Medical Sciences, Sari Medical School Sari, Iran, E-mail: Ajami36@gmail.com

Received October 31, 2012; Accepted November 20, 2012; Published Novembe 25, 2012

Citation: Saffar M-J, Ajami A,Moslemizadeh N, Saffar H, Khalilian A-R (2012) Prepregnancy Pertussis Immunization: Effect on Materno-Neonatal Antibody Titers and Infant Immune Response to Whole-Cell Pertussis Vaccination. J Vaccines Vaccin 3: 157. doi: 10.4172/2157-7560.1000157

Copyright: () 2012 Mohammed-Jafar S, et al. This is an open-access article distributed under the terms of the Creative Commons Attribution License, which permits unrestricted use, distribution, and reproduction in any medium, provided the original author and source are credited. 
Citation: Saffar M-J, Ajami A,Moslemizadeh N, Saffar H, Khalilian A-R (2012) Prepregnancy Pertussis Immunization: Effect on Materno-Neonatal Antibody Titers and Infant Immune Response to Whole-Cell Pertussis Vaccination. J Vaccines Vaccin 3: 157. doi: 10.4172/21577560.1000157

Page 2 of 5

antibodies on the infant immune response to recommended whole - cell Pertussis primary vaccination.

\section{Subjects and Methods}

A prospective study was conducted in two phases from April - 1, 2008- to 30 October 2011 (43 months study period) in primary health centers (PHC) affiliated with Mazandaran University of Medical Science, Sari - Iran. The primary objective of the first part of the study was to evaluate the safety and kinetics of immunological response to the administration of a booster dose of a $\mathrm{dTaP}$ vaccine, in vaccinees over 43 months study period. The research population included healthy 18-35 year old women with pregnancy planning, and also young women who referred to $\mathrm{PHC}$ for before marriage laboratory screening. The main objective for the second phase of the study was to determine the placental transfer rates of pertussis specific antibodies among studied women who became pregnant and delivered a fullterm- infant and their newborns via paired blood sample obtained during labor or shortly thereafter. In addition, immunologic responses of offspring's to the first, third, and fourth dose of scheduled wholecell pertussis containing vaccine [DTwP vaccine: Razi institute - Iran: diphtheria toxin $15 \mathrm{Lf}$, tetanus toxoid 10Lf, pertussis 16 protective unit] was measured. The study was approved by Medical Ethic Committee of the University. Informed written consent was obtained from both spouses. All subjects were assigned to receive one dose of dTaP vaccine [Covaxis: Sanofi pasteur MSD; PT 2.5, FHM 5, FIM 5, PRN 3 all $\mu$ g, T 5 Lf, D 2 Lf]. Excluding criteria were pregnancy (negative urine test), history of receiving dT vaccine within the past five years, recipients of immunoglobulin, blood and blood products within the past three months, chronic illnesses and immunosuppression and previous allergy history to pertussis containing vaccine. Before vaccine administration, Five ml blood was drawn from each participant. A single dose of dTap vaccine was administered intramuscularly into deltoid muscle. Serious adverse events such as fever 38.5, erythema/indurations $50 \mathrm{~mm}$, convulsion for the first week after vaccination were recorded through contacts with health care providers. To determine the immunologic response to pertussis vaccination and also, the kinetics of pertussis related antibodies among vaccinees over a period of 43 months postvaccination blood samples were obtained at interval months of 1,12 , 28 , and 43 . To evaluate placental transfer rates of pertussis- specific antibodies to their offsprings, materno-neonatal paired blood samples were collected at the time of delivery or shortly thereafter within 4 days of delivery from studied women who developed pregnancy during the study period. Transplacental transfer ratio was estimated by dividing the mean concentration antibody (MCA) values of neonates to mothers. During the study period, immunologic responses of infants (offsprings) to scheduled routine $\mathrm{DTwP}$ vaccination were determined 4 weeks after administration of the first, third, and fourth doses of the DTwP vaccine. All sera were stored at $-20^{\circ} \mathrm{C}$ until assessment at the university laboratory. Samples were tested quantitatively for anti - Pertussis IgG antibodies using Bordetella. pertussis IgG ELISA kit [anti PT, anti FMA, anti LPS together, IBL, Hamburg - Germany] according to the manufacturer instructions. Cut-off value of $\geq 24 \mathrm{EU} /$ $\mathrm{ml}$ was considered positive and protective, and lower titer as negative. Immunologic responses to the pertussis component of the vaccine was defined as seroconversion in those seronegative and/or increase $>2$ fold in antibody titers among those seropositive before vaccination. MCA levels with $95 \%$ confidence Interval $\left(\mathrm{CI}_{95}\right)$ and the percentile of seropositive subjects were calculated in different sampling points. A descriptive statistical analysis method was used to analyze the results. Paired - $\mathrm{t}$ test was used to compare the data collected before and after vaccination, and also, between data collection at different points of post vaccination. $\mathrm{P}<0.05$ was considered to be statistically significant.

\section{Results}

For the first part of the study, a total of 114 women were recruited with the mean age of 24 (SD 7.22) years. Among them 79(69.3\%) with MCA level of 68.19 (38.46) Eu/mL (CI: 60.15-77.43) were found seropositive. Four weeks after booster dose administration MCA titers and the number of seropositive subjects increased significantly: MCA 152.82 (70.31) vs. 68.19 (38.46) EU/mL, P - 0.0001 and $93.8 \%$ vs. 69.3\%: P - 0.0001, respectively. There was no significant difference of immunologic responses to pertussis vaccination between two groups of seronegative $v s$. seropositive subjects before immunization; 154.58 (64.19) vs. 149.81(73.18) $\mathrm{EU} / \mathrm{mL}, \mathrm{P}=\mathrm{NS}$, and $96.87 \%$ vs. $92.6 \%, \mathrm{P}=\mathrm{NS}$ (fisher exact test), respectively. As shown in table 1, the pertussis IgG antibodies titers and the relative number of seroimmune subjects decreased over time. These decreasing rates were more rapid within the first 12 months which became slower thereafter. After 43 months, $72.3 \%$ of women preserved significantly higher MCA levels compared with MCA titer before vaccination; $\mathrm{P}<0.05$.

During the study period $24(21 \%)$ pregnancies occurred. The research proceeded by seven mother-newborn pairs who agreed to stay in the study. Also, four other mothers agreed to participate in the study and delivered the blood draws of their 3 month old babies after receiving the first and third doses of pertussis vaccine. As shown in table 2 the MCA titers of mothers and their newborns at the time of delivery were $77.47(27.85) \mathrm{EU} / \mathrm{mL}$ and $82.62(21.03) \mathrm{EU} / \mathrm{mL}$, respectively with placental transfer ratio of $106.6 \%$. The anti-pertussis MCA levels after administration of the first, third and fourth doses of DTwP vaccine were 36.17(7.49) (CI: 44.03-28.30), 94.44(18.05) (CI: 108.30-80.57) and $141.50(40.90)(\mathrm{CI}: 206.60-76.41) \mathrm{EU} / \mathrm{mL}$, respectively.

\section{Discussion}

The seroprevalence rate found in this study supports our two previous seroepidemiological studies $[19,20]$ that indicated more than two third of young adult population and childbearing age women are seroimmune to pertussis infection. The data shows that pertussis is endemic in the region probably due to circulation of $\mathrm{B}$. pertussis bacterium in the community. So, there is a risk of transmission to

\begin{tabular}{|c|c|c|c|c|}
\hline Groups & $\begin{array}{c}\text { Total } \\
\text { number a } \\
\text { Positive (\%) }\end{array}$ & $\begin{array}{c}\mathrm{MCA}(\mathrm{SD}){ }^{\mathrm{b}} \\
\mathrm{EU} / \mathrm{mL}\end{array}$ & $\mathrm{Cl}_{95}$ & $\begin{array}{l}\text { P value for } \\
\text { MCA levels }\end{array}$ \\
\hline $\begin{array}{l}\text { Group A } \\
\text { before boosting }\end{array}$ & $114 / 79(69.3)$ & $68.19(38.46)$ & $60.15-77.43$ & $\begin{array}{l}\text { Grup A vs. B. } \\
P<0.0001\end{array}$ \\
\hline $\begin{array}{l}\text { Group B 4-6 wks } \\
\text { after }\end{array}$ & 113/106(93.8) & 152.82(70.31) & 137.6-164.6 & $\begin{array}{l}\text { Grup B1 vs. B2. } \\
\mathrm{P}=0.776\end{array}$ \\
\hline $\begin{array}{l}\mathrm{B}_{1} \text { : Seronegative } \\
\text { women before }\end{array}$ & $32 / 31(96.87)$ & $154.58(64.19)$ & $132.90-177.20$ & \\
\hline $\begin{array}{l}\mathrm{B}_{2} \text { : Seropositive } \\
\text { women before }\end{array}$ & $75 / 81(92.6)$ & $149.81(73.18)$ & $130.90-166.80$ & $\begin{array}{l}\text { Grup A vs.C. } \\
\mathrm{P}<0.0001\end{array}$ \\
\hline $\begin{array}{l}\text { Group C } 12 \\
\text { months after }\end{array}$ & $97 / 80(82.4)$ & $107.00(44.75)$ & $97.08-117.00$ & $\begin{array}{l}\text { Grup A vs.D. } \\
P<0.001\end{array}$ \\
\hline $\begin{array}{l}\text { Group D } 28 \\
\text { months after }\end{array}$ & $68 / 52(76.5)$ & $91.38(40.10)$ & $80.22-102.50$ & $\begin{array}{l}\text { Grop D vs. E, } \\
P=\text { ns }\end{array}$ \\
\hline $\begin{array}{l}\text { Group E: } 43 \\
\text { months after }\end{array}$ & 47/34(72.3) & 76.71(26.49) & $67.46-85.95$ & $\begin{array}{l}\text { Group A vs. E, } \\
P<0.05\end{array}$ \\
\hline
\end{tabular}

aP value differences between seropositive subjects in each studied group: $A$ vs. $B$ $P<0.0001$; $A$ vs. $C$ : $P<0.05$; $A$ vs. $D: P=n s ; A$ vs. $E: P=n s$

${ }^{\mathrm{b}} \mathrm{MCA}$ : mean concentration of antibodies

Table 1: Immunologic responses of studied women to one dose of dTaP booster immunization, and the kinetics of seroimmunity during 43 months study period. Sari - Iran 2008-2011 
Citation: Saffar M-J, Ajami A,Moslemizadeh N, Saffar H, Khalilian A-R (2012) Prepregnancy Pertussis Immunization: Effect on Materno-Neonatal Antibody Titers and Infant Immune Response to Whole-Cell Pertussis Vaccination. J Vaccines Vaccin 3: 157. doi: 10.4172/21577560.1000157

Page 3 of 5

\begin{tabular}{|l|l|l|l|}
\hline & \multicolumn{1}{|c|}{$\begin{array}{c}\text { Number of studied } \\
\text { infant }\end{array}$} & MCA(SD) EU/mL & \multicolumn{1}{|c|}{$\mathbf{C I}_{95}$} \\
\hline Mother & 7 & $77.47(27.85)$ & $101.81-45.82$ \\
\hline Newborn & 7 & $82.62(21.03)$ & $98.35-56.32$ \\
\hline 3 month old infants & 11 & $36.17(7.49)$ & $44.03-28.30$ \\
\hline 7 month old infants & 11 & $94.44(18.30)$ & $108.30-80.57$ \\
\hline $\begin{array}{l}19-20 \text { month old } \\
\text { infants }\end{array}$ & 4 & $141.50(40.90)$ & $206.60-76.41$ \\
\hline
\end{tabular}

aDTwP: diphtheria and tetanus toxoids, whole -cell pertussis vaccine for children. ${ }^{\mathrm{b}}$ Transplacental transfer ratio of antibodies: 82.62 to $77.47: 106.60 \%$

Table 2: Transplacental transfer ratio of maternal pertussis antibodies to the newborn, and Infants immunologic response to routine DTwPa vaccination, Sari-Iran: 2008-2011.

the susceptible young infants and other unprotected individuals. As expected and were reported in other studies [2,21], dTap vaccine was safe and highly immunogenic, and pre- existing antibody did not influence immune response rates to booster immunization [2,21].

Several studies revealed that pertussis vaccine-induced and natural - infection immunity wane overtime [22,23], and may become undetectable over 3-10 years. Prolong follow - up of immunized women allowed us to determine the kinetics of antibodies induced by boosting. Results indicated that both seroprevalence rate and MCA levels decreased over time. However, $72.3 \%$ of vaccinated women found to have significantly higher MCA levels compared with titer of that before vaccination. Some reports of the duration of immunity after dTap booster immunization in adolescents and adults revealed that seroimmunity induced by booster immunization is somewhat maintained for more than five years in significant proportions of the vaccines [24-28]. Three years after dTap booster dose of adult population in Australia. McIntyre et al. [27] demonstrated that antibodies against FHA,PT, PRN pertussis antigens were preserved in nearly all subjects. Our study findings corespond with an adult dTap trial in the U.S [28] which showed five years after booster immunization of adults, $65 \%$, $89 \%$ and $99 \%$ of studied subjects remained seroimmune to PT, PRN and FHA antigens, respectively [28].

Antibody titers against pertussis are correlated with protection in human $[17,18]$. Although protective levels for antibodies have not been established, low levels correlated susceptibility to pertussis. In a recent study lack of maternal antibody has been proposed to be a risk factor for infant pertussis [4]. Active placental transfer of maternal pertussis-specific IgG antibodies has been observed resulting in higher levels of pertussis-related antibodies available to the newborn infants. More concentrations of antibodies in neonates causes longer time protection $[3,14,16]$. Transplacentally acquired pertussis antibodies concentrations in newborn infants were found to decline with a halflife of 6-7 weeks [29,30], and according to basic levels, most infants had no detectable antibody to pertussis by the time they were 2-6 month of age; higher titer longer duration $[29,30]$. In the present study higher titers of maternal antibody was observed at delivery compared with pre-booster. As anticipated due to active placental transfer of maternal IgG antibodies, higher MCA levels in the newborn infants than those of the mothers were detected. The relatively high level of antibody observed in the neonates in this study, can presumably cover the gap of pertussis susceptibility among offsprings for some weeks. In a similar study leuradin et al. [31] evaluated the effects of prepregnancy pertussis booster dose on maternal antibody titers in young infants after vaccinating nonpregnant women between two consecutive pregnancies. They found significantly higher antibody levels in cord blood and in blood of one-month old infants compared with their siblings born before the booster dose administration.

A major concern associated with maternally-derived immunity during early infancy period is the possible interference with childhood active immunization since pre-existing antibodies achieved by placental transfer could influence the infants immune response to the scheduled primary vaccination $[3,15,16,29,30]$. The suppressive effect depends on the ratio of maternal antibody concentrations in the infant at the time of vaccination and the dose of antigens used to vaccinate the infant [32]. The inhibitory influence of high - titers maternal antibodies on infant immune response to DTaP vaccine was not reported [33], but few studies $[29,33]$ suggested that they could suppress infant immune response by DTwP vaccines $[29,33]$. However, this impact was not seen in the present and our earlier studies [19]. In a previous study, the immunogenicity of DTwP vaccine was investigated in two-month old infants considering the presence or absence of maternally-originated pertussis antibodies which showed no significant difference in immune response rates between two groups of infants [19]. Similarly, in the present study after administration of the first dose of DTwP vaccine, protective levels of pertussis antibodies were detected in all infants. Also, after receiving the third and fourth doses of vaccine, robust responses were observed. Most developing countries are using DTwP vaccines for the primary immunization schedule, therefore, further studies with larger sample size should address the influence of pre-existing hightiter pertussis specific antibodies on infant immune response to DTwP active immunization to confirm this finding.

In this study we found the safety profile and high immunologic response to dTap booster immunization, relatively long-term preservation of higher concentrations of antibodies in vaccinees, efficient active placental transfer of specific antibodies to the newborns, and importantly, no inhibitory influence of pre-existing antibody on infant immune response to $\mathrm{DTw} \mathrm{P}$ vaccine. Therefore, it seems reasonable to consider prepregnancy boosting as an alternative strategy to protect young infant against pertussis since birth even in the community with DTwP vaccine immunization program.

Other vaccination strategies with different advantages and disadvantages can be implemented [7,13-15] to protect susceptible neonates and young infants against pertussis. Ideally, each strategy should offer protection until immunity is gained by the primary vaccination programs [11-15]. No strategy on its own is appropriate for all countries because approaches to pertussis immunization vary widely, as does vaccine availability. Each country should consider the advantages and disadvantages of different strategies to determine the superiority of one approach over the others. Universal adolescents and adults periodic booster immunization is a logical goal for ultimate elimination of pertussis. This strategy in theory reduce the rate of infection in this age groups as the main source of infection, develop herd immunity, immunity, diminishing reservoirs of pertussis and minimizing transmission of the infection to susceptible population specially young infants [11,12]. However, high costs, low levels of compliance among adults, and lack of widely available ap vaccine are among the main impediments to achieving successful vaccination. Therefore, they approach cannot be helpful to protecting young infants against pertussis as a short-term strategy.

Despite recommendation from the U.S. and Canada Advisory Committee on Immunization Practices (ACIP), that all adolescentsadults should have a single booster dose with dTap vaccine, dTap vaccination coverage in this age group remained low. In 2008, only $5.9 \%$ of adults had received a dose of dTap, and coverage among adults with infant contact was estimated to be $5 \%$. Therefore, this approach 
Citation: Saffar M-J, Ajami A,Moslemizadeh N, Saffar H, Khalilian A-R (2012) Prepregnancy Pertussis Immunization: Effect on Materno-Neonatal Antibody Titers and Infant Immune Response to Whole-Cell Pertussis Vaccination. J Vaccines Vaccin 3: 157. doi: 10.4172/21577560.1000157

Page 4 of 5

cannot be helpful in protecting young infants against pertussis [34] as a short-term strategy.

There is good evidence that parents and other close contacts are the main and most important sources of pertussis infection for vulnerable infants $[8,9]$. Selective immunization of new parents (cocoon strategy), and also other family close contacts could be a logical approach to protect young infants against pertussis. Several studies have provided evidence that this strategy could be helpful [12]. As demonstrated by Halperin et al. [35]. vaccination during the immediate postpartum period ensures high antibody levels in vaccinees but the immune response is not sufficiently rapid to protect neonates during the first weeks of life [36]. Furthermore, cocooning is expensive, logistically complicated, and does not directly benefit the infant [37]. Given these barriers, it is not surprising that the uptake of postpartum maternal vaccination has been low in countries where this intervention is recommended [36].

Neonatal immunization with acellular pertussis vaccines is another strategy to cover early infancy susceptibility gap [13-15], and has been shown to be safe, and induce both humoral and cellular immune response in vaccinated neonates. However, these approaches still need some weeks to build up immunity [13-16]. Some studies [38-41] on neonatal pertussis vaccination have been published indicating different results. In all trials, immunization was safe and well tolerated. In three trials [38-40], neonates were primed with monovalent ap vaccine with some differences in the schedule and vaccine components. Earlier antibodies responses were shown in all three studies and were compared with infants who were vaccinated according to recommended program at 2-3 month of age. No immune tolerance was observed in followup. However, vaccine interference with other vaccine antigens was reported. In a DTap vaccine trial [41]. Halasa et al [41] compared the safety and immunogenicity of an additional birth dose of DTap vaccine with routine program. This study showed a significant lower response to diphtheria toxoid and 3 of 4 pertussis antigens. Compared with control at 6 months of age, pertussis antibody level were similar between two groups, but at 7 months, lower levels of pertussis antibody in neonatal vaccination group was observed. Researchers suggested that larger and more detailed studies of ap vaccine at birth are needed to assess its influence on other antibody responses and the potential of this approach to reduce morbidity and mortality from pertussis in the first three months of life [38-41].

One immediate method achieving sufficient pertussis-specific IgG concentrations in newborn infants is vaccinating pregnant woman $[13,15,16,21,42]$. This strategy could provide protection to infant since birth until immunity is gained through active immunization. The U.S. ACIP recommended that pregnancy is not a contraindication for vaccination with $d$ Tap vaccines $[2,21]$. However, vaccination against pertussis during pregnancy has significant practical hurdle including vaccine licensure concern regarding side effects in mother and fetus, low acceptance of both public and obstetricians, and possible inhibitory effect of high-titers maternal antibody on infant immune response to DTP active immunization. These make dTaP clinical trials during pregnancy problematic, and limited numbers of published studies are available [14-16]. Gall [42] has advocated maternal immunizations as a method of protecting neonates from pertussis disease until active immunity is present [42]. In a recent study [43] to determine the effects of $\mathrm{dTaP}$ maternal immunization during pregnancy on maternal and neonatal sera antibody levels [43], by Gall et al. it was clearly shown that vaccination was safe and well tolerated, and vaccinated women had significantly higher antibody levels at the time of delivery and maternal antibodies actively transferred to newborn babies [43].

Mooi and de Greeff [15] in a review on the potential preventive strategies to improve protection against pertussis among young infants proposed that maternal vaccination might be an effective way to decrease morbidity and mortality caused by pertussis in neonates and young infants. However, more studies should be carried out to establish a safe and effective way to protect young infants against pertussis.

\section{Conclusion}

This study revealed: safety and immunogenicity profile, longterm persistence of antibodies achieved after boosting, efficient placental transfer rates of antibodies to the newborn babies, and infant immune response to scheduled DTwP vaccination, therefore targeted prepregnancy $\mathrm{dTaP}$ booster immunization could be an alternative approach to protect susceptible young infants against severe pertussis infection. Further studies with larger sample size and longer duration to explore its usefulness as a strategy to prevent life-threatening infection in very young infants are recommended.

\section{Acknowledgment}

This project was funded by deputy for research of Mazandaran University of Medical Sciences, Grant No: 87-32/87.5.10. The authors wish to thank enrolled women and their families, public health staff for their help in recruiting the subjects and blood sampling for this study. Also, special thanks go to Abedian, F and Mirabi, $\mathrm{F}$ for performing the tests, and shahabian, $\mathrm{M}$ for editing this manuscript.

\section{References}

1. Cherry JD, Heininger U (2009) Pertussis and other Bordetella infections Textbook of pediatric infectious diseases. (6thedn), Elsevier Saunders.

2. Edwards KM, Decker MD (2008) Pertussis vaccines. (5thedn), Vaccines Elsevier-Saunders.

3. Van Rie A, Wendelboe AM, Englund JA (2005) Role of maternal pertussis antibodies in infants. Pediatr Infect Dis J 24: S62-S65.

4. Healy CM, Rench MA, Edwards KM, Baker CJ (2006) Pertussis serostatus among neonates born to Hispanic women. Clin Infect Dis 42: 1439-1442.

5. Greenberg DP, von König $\mathrm{CH}$, Heininger U (2005) Health burden of pertussis in infants and children. Pediatr Infect Dis J 24: S39-43.

6. Vitek CR, Pascual FB, Baughman AL, Murphy TV (2003) Increase in deaths from pertussis among young infants in the United States in the 1990s. Pediatr Infect Dis J 22: 628-634.

7. Cortese MM, Baughman AL, Zhang R, Srivastava PU, Wallace GS (2008) Pertussis hospitalizations among infants in the United States, 1993 to 2004 Pediatrics 121: 484-492.

8. Bisgard KM, Pascual FB, Ehresmann KR, Miller CA, Cianfrini C, et al. (2004) Infant pertussis: who was the source? Pediatr Infect Dis J 23: 985-989.

9. Wendelboe AM, Njamkepo E, Bourillon A, Floret DD, Gaudelus J, et al. (2007) Transmission of Bordetella pertussis to young infants. Pediatr Infect Dis J 26: 293-299.

10. Schellekens J, von König CH, Gardner P (2005) Pertussis sources of infection and routes of transmission in the vaccination era. Pediatr Infect Dis J 24: S19-24.

11. Forsyth KD, Wirsing von Konig CH, Tan T, Caro J, Plotkin S (2007) Prevention of pertussis: recommendations derived from the second Global Pertussis Initiative roundtable meeting. Vaccine 25: 2634-2642.

12. de Greeff SC, Mooi FR, Westerhof A, Verbakel JM, Peeters MF, et al. (2010) Pertussis disease burden in the household: how to protect young infants. Clin Infect Dis 50: 1339-1345.

13. Mclntyre P, Wood N (2009) Pertussis in early infancy: disease burden and preventive strategies. Curr Opin Infect Dis 22: 215-233.

14. Wood N, Siegrist CA (2011) Neonatal immunization: where do we stand? Curr Opin Infect Dis 24: 190-195. 
Citation: Saffar M-J, Ajami A,Moslemizadeh N, Saffar H, Khalilian A-R (2012) Prepregnancy Pertussis Immunization: Effect on Materno-Neonatal Antibody Titers and Infant Immune Response to Whole-Cell Pertussis Vaccination. J Vaccines Vaccin 3: 157. doi: 10.4172/21577560.1000157

15. Mooi FR, de Greeff SC (2007) The case for maternal vaccination against Pertussis. Lancet Infect Dis 7: 614-624.

16. James E, Crowe Jr (2011) Preventation of fetal and early life Infectious through maternal-nenonatal immunization. (7thedn), Infectious Diseases of the Fetus and Newborn.

17. Storsaeter J, Hallander HO, Gustafsson L, Olin P (2003) Low levels of antipertussis antibodies plus lack of history of pertussis correlate with susceptibility after household exposure to Bordetella pertussis. Vaccine 21 : 3542-3549.

18. Taranger J, Trollfors B, Lagergård T, Sundh V, Bryla DA, et al. (2000) Correlation between pertussis toxin IgG antibodies in postvaccination sera and subsequent protection against pertussis. J Infect Dis 181: 1010-1013.

19. Saffar MJ, Ajami A, Khalilian AR, Qaheri A, Saffar H (2007) Pertussis seroimmunity among mother-infant pairs and infant immune response to pertussis vaccination. Indian Pediatr 44: 916-918.

20. Saffar MJ, Khalilian AR, Rafee AR, Parsaei MR, Imanikhani S, et al. (2012) Bordetella pertussis IgG and IgA antibodies seroprevalence among 1-35 y-old population: the role of subclinical pertussis infection. Indian J Pediatr 79: 353-357.

21. American Academy of Pediatrics (2009) Pertussis. Red Book: 2009 Report of the Committee on Infectious Diseases. (28thedn), Elk Grove Village, American Academy of Pediatrics.

22. Esposito S, Agliardi T, Giammanco A, Faldella G, Cascio A, et al. (2001) Longterm pertussis-specific immunity after primary vaccination with a combined diphtheria, tetanus, tricomponent acellular pertussis, and hepatitis $B$ vaccine in comparison with that after natural infection. Infect Immun 69: 4516-4520.

23. Wendelboe AM, Van Rie A, Salmaso S, Englund JA (2005) Duration of immunity against pertussis after natural infection or vaccination. Pediatr Infect Dis J 24: S58-S61.

24. Le T, Cherry JD, Chang SJ, Knoll MD, Lee ML, et al. (2004) Immune responses and antibody decay after immunization of adolescents and adults with an acellular pertussis vaccine: the APERT Study. J Infect Dis 190: 535-544.

25. Barreto L, Guasparini R, Meekison W, Noya F, Young L, et al. (2007) Humoral immunity 5 years after booster immunization with an adolescent and adult formulation combined tetanus, diphtheria, and 5-component acellular pertussis vaccine. Vaccine 25: 8172-8179.

26. Bailleux F, Coudeville L, Kolenc-Saban A, Bevilacqua J, Barreto L, et al (2008) Predicted long-term persistence of pertussis antibodies in adolescents after an adolescent and adult formulation combined tetanus, diphtheria, and 5 -component acellular pertussis vaccine, based on mathematical modeling and 5-year observed data. Vaccine 26: 3903-3908.

27. McIntyre PB, Turnbull FM, Egan AM, Burgess MA, Wolter JM, et al. (2004) High levels of antibody in adults three years after vaccination with a reduced antigen content diphtheria-tetanus-acellular pertussis vaccine. Vaccine 23: 380-385.

28. Edelman K, He Q, Mäkinen J, Sahlberg A, Haanperä M, et al. (2007) Immunity to pertussis 5 years after booster immunization during adolescence. Clin Infect Dis 44: 1271-1277.
29. Van Savage J, Decker MD, Edwards KM, Sell SH, Karzon DT (2008) Natural history of pertussis antibody in the infant and effect on vaccine response. Vaccine 26: 3903-3908.

30. Edwards KM (2003) Pertussis: an important target for maternal immunization. Vaccine 21: 3483-3486.

31. Leuridan E, Hens N, Peeters N, de Witte L, Van der Meeren O, et al. (2011) Effect of a prepregnancy pertussis booster dose on maternal antibody titers in young infants. Pediatr Infect Dis J 30: 608-610.

32. Siegrist CA (2003) Mechanisms by which maternal antibodies influence infant vaccine responses: review of hypotheses and definition of main determinants. Vaccine 21: 3406-3412.

33. Englund JA, Anderson EL, Reed GF, Decker MD, Edwards KM, et al. (1995) The effect of maternal antibody on the serologic response and the incidence of adverse reactions after primary immunization with acellular and whole-cell pertussis vaccines combined with diphtheria and tetanus toxoids. Pediatrics 96: $580-584$.

34. Centers for Disease Control and Prevention (CDC) (2010) Tetanus and pertussis vaccination coverage among adults aged $\geq 18$ years --- United States, 1999 and 2008. MMWR Morb Mortal Wkly Rep 59: 1302-1306.

35. Halperin BA, Morris A, Mackinnon-Cameron D, Mutch J, Langley JM, et al (2011) Kinetics of the antibody response to tetanus-diphtheria-acellular pertussis vaccine in women of childbearing age and postpartum women. Clin Infect Dis 53: 885-892.

36. Munoz F, Englund J (2011) Infant pertussis: is cocooning the answer? Clin Infect Dis 53: 893-896.

37. Westra TA, de Vries R, Tamminga JJ, Sauboin CJ, Postma MJ (2010) Costeffectiveness analysis of various pertussis vaccination strategies primarily aimed at protecting infants in the Netherlands. Clin Ther 32: 1479-1495

38. Belloni C, De Silvestri A, Tinelli C, Avanzini MA, Marconi M, et al. (2003) Immunogenicity of a three-component acellular pertussis vaccine administered at birth. Pediatrics 111: 1042-1045.

39. Knuf M, Schmitt HJ, Wolter J, Schuerman L, Jacquet JM, et al. (2008) Neonata vaccination with an acellular pertussis vaccine accelerates the acquisition of pertussis antibodies in infants. J Pediatr 152: 655-660, 660.

40. Wood N, McIntyre P, Marshall H, Roberton D (2010) Acellular pertussis vaccine at birth and one month induces antibody responses by two months of age. Pediatr Infect Dis J 29: 209-215.

41. Halasa NB, O'Shea A, Shi JR, LaFleur BJ, Edwards KM (2008) Poor immune responses to a birth dose of diphtheria, tetanus, and acellular pertussis vaccine. J Pediatr 153: 327-332.

42. Gall SA (2008) Vaccines for pertussis and influenza: recommendations for use in pregnancy. Clin Obstet Gynecol 51: 486-497.

43. Gall SA, Myers J, Pichichero M (2011) Maternal immunization with tetanusdiphtheria-pertussis vaccine: effect on maternal and neonatal serum antibody levels. Am J Obstet Gynecol 204: 334 e1-e5. 